\title{
The Effect of (Ag, Ni, Zn)-Addition on the Thermoelectric Properties of Copper Aluminate
}

\section{Shun-ichi Yanagiya ${ }^{1,2, *}$, Ngo Van Nong ${ }^{2}$, Jianxiao $\mathrm{Xu}^{2}$ and Nini Pryds ${ }^{2}$}

1 Department of Electrical and Electronic Engineering, Hakodate National College of Technology, 14-1 Tokura, Hakodate, Hokkaido 042-8501, Japan

2 Fuel Cells and Solid State Chemistry Division, Risø National Laboratory for Sustainable Energy, Technical University of Denmark, Roskilde 4000, Denmark; E-Mails: ngno@risoe.dtu.dk (N.N.); jiax@risoe.dtu.dk (J.X.); nipr@risoe.dtu.dk (N.P.)

* Author to whom correspondence should be addressed; E-Mail: yanagiya@hakodate-ct.ac.jp; Tel.: +81-138-59-6423; Fax: +81-138-59-6423.

Received: 21 December 2009; in revised form: 7 January 2010 / Accepted: 8 January 2010 / Published: 11 January 2010

\begin{abstract}
Polycrystalline bulk copper aluminate $\mathrm{Cu}_{1-\mathrm{x}-\mathrm{y}} \mathrm{Ag}_{\mathrm{x}} \mathrm{B}_{\mathrm{y}} \mathrm{AlO}_{2}$ with $\mathrm{B}=\mathrm{Ni}$ or $\mathrm{Zn}$ were prepared by spark plasma sintering and subsequent thermal treatment. The influence of partial substitution of $\mathrm{Ag}, \mathrm{Ni}$ and $\mathrm{Zn}$ for $\mathrm{Cu}$-sites in $\mathrm{CuAlO}_{2}$ on the high temperature thermoelectric properties has been studied. The addition of $\mathrm{Ag}$ and $\mathrm{Zn}$ was found to enhance the formation of $\mathrm{CuAlO}_{2}$ phase and to increase the electrical conductivity. The addition of $\mathrm{Ag}$ or $\mathrm{Ag}$ and $\mathrm{Ni}$ on the other hand decreases the electrical conductivity. The highest power factor of $1.26 \times 10^{-4} \mathrm{~W} / \mathrm{mK}^{2}$ was obtained for the addition of $\mathrm{Ag}$ and $\mathrm{Zn}$ at $1,060 \mathrm{~K}$, indicating a significant improvement compared with the non-doped $\mathrm{CuAlO}_{2}$ sample.
\end{abstract}

Keywords: copper aluminate; oxide material; element addition; thermoelectric properties

\section{Introduction}

Thermoelectric materials have been widely studied over the past decades owing to their potential application as a thermoelectric convertor of waste heat into electricity [1]. This energy conversion technique has the advantage of being maintenance-free because of the ability to operate without moving parts and/or chemical reactions. However, this technique has not been widely used in 
industrial applications so far due to the low thermoelectric conversion efficiency. In general, the performance of a thermoelectric material is evaluated by the figure of merit $Z$ or the dimensionless figure of merit $Z T$, as follows:

$$
Z T=\frac{\sigma S^{2}}{\kappa} T
$$

where $\sigma, S, \kappa$ and $T$ are the electrical conductivity, Seebeck coefficient, thermal conductivity and absolute temperature, respectively. To achieve high $Z$, a large $S$, a high $\sigma$ and a small $\kappa$ are required. However, it is difficult to increase $Z$ because these three parameters are all functions of carrier concentration and are interrelated with each other. There are some approaches to increase figure of merit $Z$ : an optimization of carrier concentration, which varies between $10^{19}$ to $10^{21}$ carriers per $\mathrm{cm}^{3}$ for common semiconductors [1,2], lowering the thermal conductivity by heavier element substitution [3] and nanostructuring of the materials [4].

Many kinds of materials are currently under investigation, which include $\mathrm{Bi}_{2} \mathrm{Te}_{3}$ [5], $\mathrm{PbTe}$ [6] based materials, $\mathrm{SiGe}$ [7], silicides [8], $\beta-\mathrm{Zn}_{4} \mathrm{Sb}_{3}$ [9], skutterudites [10], half-Heusler alloys [11] and clathrate compounds [12]. In addition, since the first report of $\mathrm{NaCo}_{2} \mathrm{O}_{4}$ in 1997 [13], various new oxide materials with good thermoelectric properties such as $\mathrm{Ca}_{3} \mathrm{Co}_{4} \mathrm{O}_{9}$ system [14], ZnO [15] and $\mathrm{SrTiO}_{3}$ [16] have attracted increasing attention because of their thermal and chemical stability at high temperature in air, low toxicity, low cost and easy manufacture.

Another type of oxide material, copper aluminate $\left(\mathrm{CuAlO}_{2}\right)$, which is stable at high temperatures up to $1,400 \mathrm{~K}$ and possessing a good thermoelectric power, is expected to be another promising material for thermoelectric devices [17,18]. This type of materials has also gained much attention in the field of optoelectronic applications [19,20] due to the fact that the $\mathrm{CuAlO}_{2}$ has a direct band-gap of $3.5 \mathrm{eV}$ [21] and is a transparent conductor. $\mathrm{CuAlO}_{2}$ crystallizes in the rhombohedral, delafossite-type structure $(\mathrm{a}=2.85670 \AA, \mathrm{c}=16.9430 \AA)$ [22] and shows $p$-type semiconductivity [23]. Park et al. have investigated the thermoelectric properties of $\mathrm{CuAl}_{1-\mathrm{x}} \mathrm{Ca}_{\mathrm{x}} \mathrm{O}_{2}(0 \leq \mathrm{x} \leq 0.2)$ [24] and found that the substitution of $\mathrm{Ca}$ for $\mathrm{Al}$ up to $\mathrm{x}=0.1$ increases both the electrical conductivity and the Seebeck coefficient. Lately, the effects of $\mathrm{Mg}$ or Fe substitution for $\mathrm{Al}$ in $\mathrm{CuAlO}_{2}$ were also reported [25,26]. Among these studied elements, the highest value of power factor $\left(1.1 \times 10^{-4} \mathrm{~W} / \mathrm{mK}\right)$ was obtained for the $\mathrm{CuAl}_{0.9} \mathrm{Fe}_{0.1} \mathrm{O}_{2}$ sample at $1,140 \mathrm{~K}$. Moreover, the calculation of the electronic structure of Ni or $\mathrm{Zn}$ doped $\mathrm{CuAlO}_{2}$ using a full potential linear augmented plane-wave method, reported by Lalic et al., showed that $\mathrm{Ni}$ and $\mathrm{Zn}$ substituted for $\mathrm{Cu}$-sites act as acceptor and donor impurities, respectively [27]. As for delaffosite-type of materials, the effect of $\mathrm{Ag}$ substitution for $\mathrm{Cu}$-sites in $\mathrm{CuRhO}_{2}$ has been investigated [28]. However, to our knowledge, the effect of element substitution for $\mathrm{Cu}$-sites in $\mathrm{CuAlO}_{2}$ has not been reported to date.

In this study, we focus on the substitution of $\mathrm{Ag}, \mathrm{Ni}$ and $\mathrm{Zn}$ to $\mathrm{Cu}$-sites in $\mathrm{CuAlO}_{2}$ and systematically investigate their effects on the high temperature thermoelectric properties of these compounds. 


\section{Experimental}

\subsection{Preparation of samples}

A series of samples with the composition $\mathrm{Cu}_{1-\mathrm{x}-\mathrm{y}} \mathrm{Ag}_{\mathrm{x}} \mathrm{B}_{\mathrm{y}} \mathrm{AlO}_{2}$ with $\mathrm{B}=\mathrm{Ni}$ or $\mathrm{Zn}$ was prepared by the solid-state reaction method. Highly pure powders of $\mathrm{CuO}, \mathrm{Al}_{2} \mathrm{O}_{3}, \mathrm{NiO}, \mathrm{ZnO}$ (Sigma-Aldrich, Inc., 99.99\%) and $\mathrm{Ag}_{2} \mathrm{O}$ (Sigma-Aldrich, Inc., 99\%) were sufficiently mixed and ground in an $\mathrm{Al}_{2} \mathrm{O}_{3}$ mortar by using an automatic mill. The nominal compositions of samples are expressed as follows: $\mathrm{CuAlO}_{2}$, $\mathrm{Cu}_{0.98} \mathrm{Ag}_{0.02} \mathrm{AlO}_{2}, \mathrm{Cu}_{0.979} \mathrm{Ag}_{0.02} \mathrm{Ni}_{0.001} \mathrm{AlO}_{2}$ and $\mathrm{Cu}_{0.979} \mathrm{Ag}_{0.02} \mathrm{Zn}_{0.001} \mathrm{AlO}_{2}$. The doping level of $0.1 \%$ for $\mathrm{Ni}$ and $\mathrm{Zn}$ was chosen to generate about $2.5 \times 10^{19}$ carriers per $\mathrm{cm}^{3}$ for an optimization of carrier concentration. The mixtures were placed into a graphite die with an inner diameter of $15 \mathrm{~mm}$ and then sintered in a spark plasma sintering (SPS) machine (Sumitomo Coal Mining Co.) at 1,123 K for $20 \mathrm{~min}$ under uniaxial pressure of $30 \mathrm{MPa}$ in vacuum. After the SPS process, the samples were annealed at $1,373 \mathrm{~K}$ for $24 \mathrm{~h}$ in flowing air. The samples were cut into rectangular bars with the approximate dimension of $2 \times 3 \times 10 \mathrm{~mm}^{3}$ for measurements of the electrical conductivity and Seebeck coefficient. For thermal conductivity measurements, the samples were cut into a shape of $10 \times 10 \times 2 \mathrm{~mm}^{3}$.

\subsection{Characterization}

The crystalline structures of the samples were analyzed by X-ray diffraction (XRD) on a STOE diffractometer with $\mathrm{Cu}-\mathrm{K} \alpha$ radiation. Microstructures of the samples were observed by scanning electron microscopy (SEM) with a Hitachi TM-1000 system. The electrical conductivity and Seebeck coefficient were simultaneously measured using an ULVAC-RIKO ZEM-3 thermoelectric property measurement system under a low-pressure helium atmosphere. The thermal conductivity was determined from thermal diffusivity and specific heat measured using a Netzsch LFA-457 laser flash apparatus in a $\mathrm{N}_{2}$ atmosphere.

\section{Results and Discussion}

\subsection{Crystal structure and microstructure}

Figure 1 shows the powder XRD patterns of the samples. For the non-doped $\mathrm{CuAlO}_{2}$, all the diffraction peaks can be indexed as the rhombohedral, delafossite-type structure (standard ICDD-PDF 35-1401) except for a very small peak which belongs to the $\mathrm{CuO}$ phase at a scattering angle of $61.5^{\circ}$. With the addition of $\mathrm{Ag}$, besides the primary phase of $\mathrm{CuAlO}_{2}$, a secondary phase of $\mathrm{CuO}(\mathrm{a}=4.662 \AA$, $\mathrm{b}=3.416 \AA, \mathrm{c}=5.118 \AA, \beta=99.49^{\circ}$, ICDD-PDF: 065-2309) with a monoclinic structure was detected. As for the $\mathrm{Cu}_{0.979} \mathrm{Ag}_{0.02} \mathrm{Ni}_{0.001} \mathrm{AlO}_{2}$, two secondary phases of $\mathrm{CuO}$ and $\mathrm{CuAl}_{2} \mathrm{O}_{4}(\mathrm{a}=8.0790 \AA$, ICDDPDF: 078-1605) with a cubic structure were observed. In the case of the $\mathrm{Cu}_{0.979} \mathrm{Ag}_{0.02} \mathrm{Zn}_{0.001} \mathrm{AlO}_{2}$, the sample is found to be a single-phase of $\mathrm{CuAlO}_{2}$ without any other secondary peaks. In all the samples, no peaks belonging to the Ag were observed, indicating a complete solubility of the Ag. The chemical reaction process of $\mathrm{CuAlO}_{2}$ from the $\mathrm{CuO}$ and the $\mathrm{Al}_{2} \mathrm{O}_{3}$ is expressed by following reactions:

(1) $\mathrm{CuO}+\mathrm{Al}_{2} \mathrm{O}_{3} \rightarrow \mathrm{CuAl}_{2} \mathrm{O}_{4}$, and

(2) $\mathrm{CuAl}_{2} \mathrm{O}_{4}+\mathrm{CuO} \rightarrow 2 \mathrm{CuAlO}_{2}+1 / 2 \mathrm{O}_{2} \uparrow$. 
Therefore, it appears that the addition of $\mathrm{Ag}$ which has a larger ionic radius $\left(\mathrm{Ag}^{+}: 0.67 \AA\right)$ than the $\mathrm{Cu}\left(\mathrm{Cu}^{+}: 0.46 \AA\right)[29]$ seems to prevent the formation of only the $\mathrm{CuAlO}_{2}$ phase. As indicated by the results that the formation of the $\mathrm{CuAlO}_{2}$ phase is hindered by the addition of $\mathrm{Ag}$ and Ni. However, the addition of $\mathrm{Ag}$ and $\mathrm{Zn}$ seems to facilitate the abovementioned reactions (1) and (2).

Figure 1. Powder XRD patterns of the samples: (a) $\mathrm{CuAlO}_{2}$, (b) $\mathrm{Cu}_{0.98} \mathrm{Ag}_{0.02} \mathrm{AlO}_{2}$, (c) $\mathrm{Cu}_{0.979} \mathrm{Ag}_{0.02} \mathrm{Ni}_{0.001} \mathrm{AlO}_{2}$ and (d) $\mathrm{Cu}_{0.979} \mathrm{Ag}_{0.02} \mathrm{Zn}_{0.001} \mathrm{AlO}_{2}$ samples.

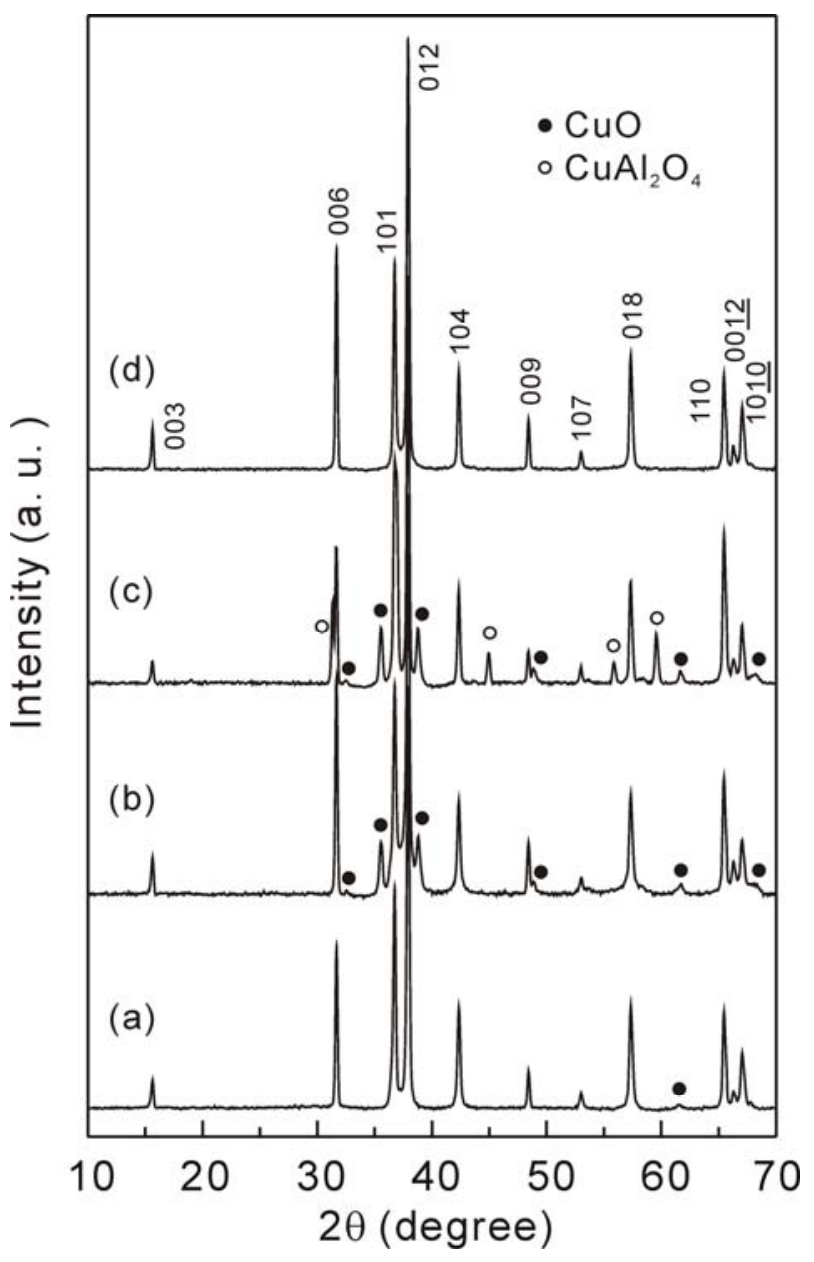

Figure 2 illustrates the SEM images of the fractured surface of the samples. It can be seen from Figures 2 (a) and (b) that the addition of Ag strongly enhances the grain growth, although a few large pores could be observed. With the addition of $\mathrm{Ni}$ or $\mathrm{Zn}$, the microstructures tend to be deteriorated due to the reduction of the grain size, as clearly shown in Figures 2 (c) and (d). Even so, the grain size of the $\mathrm{Cu}_{0.979} \mathrm{Ag}_{0.02} \mathrm{Zn}_{0.001} \mathrm{AlO}_{2}$ sample is still larger than that of the non-doped $\mathrm{CuAlO}_{2}$ sample.

\subsection{Thermoelectric properties}

The temperature dependence of the electrical conductivity $(\sigma)$ is shown in Figure 3. The $\sigma$ value of the non-doped $\mathrm{CuAlO}_{2}$ sample increases with increasing temperature over the measured temperature range, indicating a semiconducting behavior. Hamada et al. calculated the formation energy of the native defects in $\mathrm{CuAlO}_{2}$ using ab initio total energy calculation and concluded that copper vacancies are relevant to the $p$-type conductivity in $\mathrm{CuAlO}_{2}$ [30]. Also, excess oxygen contributions to hole 
generation in $\mathrm{CuAlO}_{2}$ were demonstrated by Ingram et al. [31] in the measurement of the electrical conductivity by controlling the oxygen partial pressure at a constant temperature of $800{ }^{\circ} \mathrm{C}$. The observed result revealed that the semiconducting property is due to the carriers induced by offstoichiometry.

Figure 2. The SEM images of the fractured surface of (a) $\mathrm{CuAlO}_{2}$, (b) $\mathrm{Cu}_{0.98} \mathrm{Ag}_{0.02} \mathrm{AlO}_{2}$, (c) $\mathrm{Cu}_{0.979} \mathrm{Ag}_{0.02} \mathrm{Ni}_{0.001} \mathrm{AlO}_{2}$ and (d) $\mathrm{Cu}_{0.979} \mathrm{Ag}_{0.02} \mathrm{Zn}_{0.001} \mathrm{AlO}_{2}$ samples.
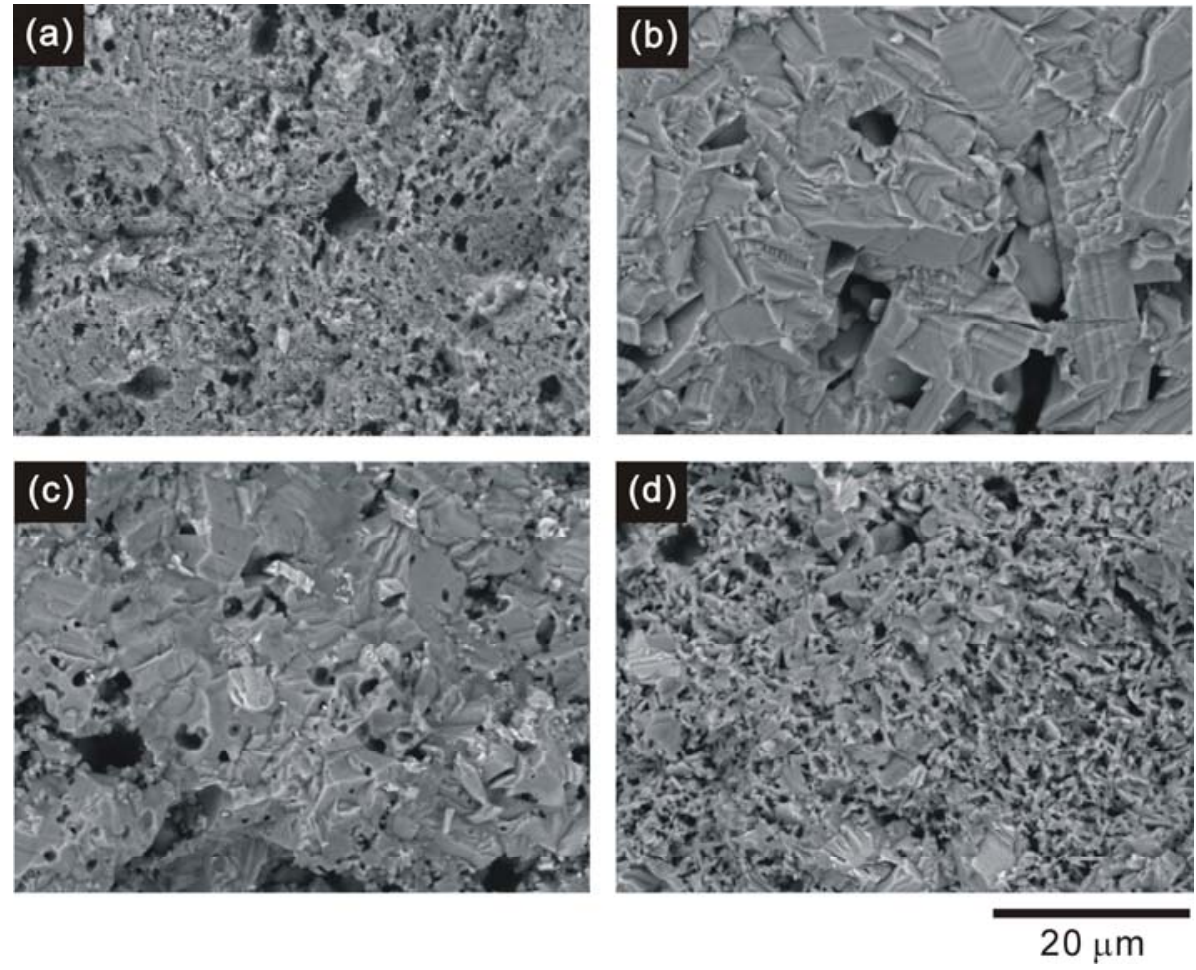

Figure 3. Temperature dependence of the electrical conductivity $\sigma$ of $\mathrm{CuAlO}_{2}$, $\mathrm{Cu}_{0.98} \mathrm{Ag}_{0.02} \mathrm{AlO}_{2}, \mathrm{Cu}_{0.979} \mathrm{Ag}_{0.02} \mathrm{Ni}_{0.001} \mathrm{AlO}_{2}$ and $\mathrm{Cu}_{0.979} \mathrm{Ag}_{0.02} \mathrm{Zn}_{0.001} \mathrm{AlO}_{2}$ samples.

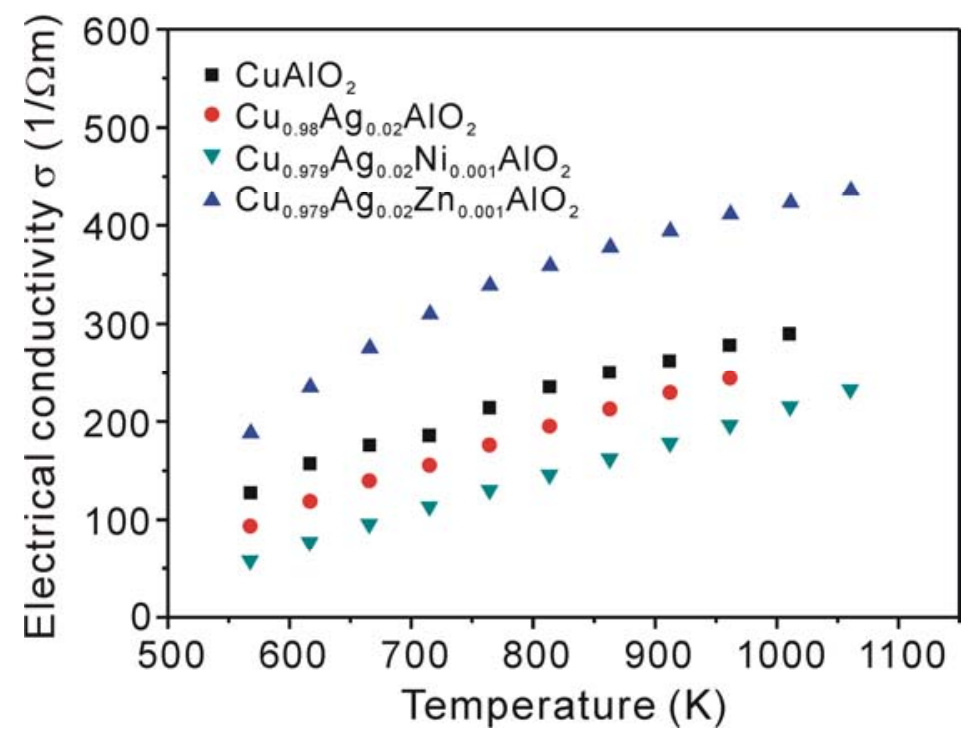

The addition of $\mathrm{Ag}$ and $\mathrm{Ni}$ to the $\mathrm{Cu}$-sites in $\mathrm{CuAlO}_{2}$ was found to decrease the electrical conductivity compared to that of the non-doped $\mathrm{CuAlO}_{2}$ sample. This is attributed to the low electrical 
conductivity of the secondary phases, i.e. $\mathrm{CuO}$ and $\mathrm{CuAl}_{2} \mathrm{O}_{4}$ which form in these samples. Moreover, the substitution of $\mathrm{Ni}$ for $\mathrm{Cu}$ will decrease the hole concentration, that is $\mathrm{Ni}^{2+}$ substituted for $\mathrm{Cu}^{+}$will act as a donor impurity contrary to the result in Ref. [27]. A similar effect of Ni substitution on the electrical conductivity was reported by Wongcharoen et al. for the Ni-doped $\mathrm{CuAlO}_{2}$ polycrystalline bulk samples [32]. It is interesting to see from Figure 3 that the addition of $\mathrm{Ag}$ and $\mathrm{Zn}$ resulted in an increase in the electrical conductivity. Generally, the substitution of $\mathrm{Zn}^{2+}$ for $\mathrm{Cu}^{+}$ions in $\mathrm{CuAlO}_{2}$ produces electrons, leading to a decrease in the hole concentration of the $p$-type $\mathrm{CuAlO}_{2}$, and thereby decreasing the electrical conductivity. However, this is not consistent with the observed results in this study. One possible reason for this inconsistency may be that the $\mathrm{Zn}^{2+}$ ion substituted not for the $\mathrm{Cu}^{+}$ ion but for the $\mathrm{Al}^{3+}$ ion, which can generate both holes and $\mathrm{Cu}$ vacancies, both contribute to the increase in the electrical conductivity.

Figure 4 shows the Seebeck coefficient $(S)$ of the samples as a function of temperature. The sign of the Seebeck coefficient is positive over the measured temperature range. These results confirm that holes are the majority carriers in these samples. The Seebeck coefficient of the samples tends to decrease with increasing temperature below $900 \mathrm{~K}$, except for the $\mathrm{Cu}_{0.979} \mathrm{Ag}_{0.02} \mathrm{Zn}_{0.001} \mathrm{AlO}_{2}$ sample, which shows a clear trend of increasing the Seebeck coefficient above $900 \mathrm{~K}$. Ingram et al. has previously reported that a small polaron hopping behavior occurring in $\mathrm{CuAlO}_{2}$ [33] in the temperature range from 950 to $1,020 \mathrm{~K}$, indicating that the number of carriers is constant in this range of temperature. However, our results showed that the Seebeck coefficient of these samples is dependent on temperature, suggesting that the carrier concentration is also temperature-dependent. Therefore, the electrical conduction of these samples in the temperature range from 573 to $1,060 \mathrm{~K}$ cannot be explained by the small polaron hopping conduction.

Figure 4. Temperature dependence of the Seebeck coefficient $S$ of $\mathrm{CuAlO}_{2}$, $\mathrm{Cu}_{0.98} \mathrm{Ag}_{0.02} \mathrm{AlO}_{2}, \mathrm{Cu}_{0.979} \mathrm{Ag}_{0.02} \mathrm{Ni}_{0.001} \mathrm{AlO}_{2}$ and $\mathrm{Cu}_{0.979} \mathrm{Ag}_{0.02} \mathrm{Zn}_{0.001} \mathrm{AlO}_{2}$ samples.

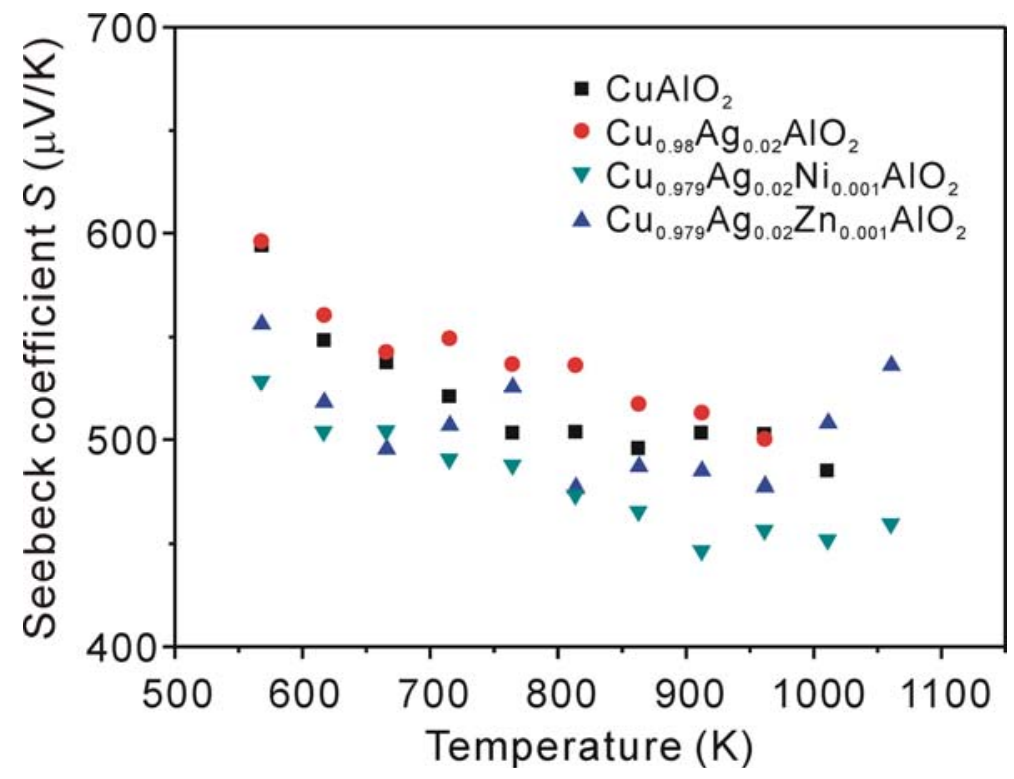

For semiconductor materials, Seebeck coefficient generally decreases with increasing carrier concentration, leading to the increase of electrical conductivity [34]. The increase in the Seebeck 
coefficient of the $\mathrm{Cu}_{0.98} \mathrm{Ag}_{0.02} \mathrm{AlO}_{2}$ sample is presumably related to the decrease in the carrier concentration. However, the Seebeck coefficient of the $\mathrm{Cu}_{0.979} \mathrm{Ag}_{0.02} \mathrm{Ni}_{0.001} \mathrm{AlO}_{2}$ sample, which has the lowest electrical conductivity, also shows the lowest value of $S$. This could be caused by the formation of the secondary phases. These results are consistent with the report in Ref. [32] for the $\mathrm{CuAl}_{1-\mathrm{x}} \mathrm{Ni}_{\mathrm{x}} \mathrm{O}_{2}$ $(\mathrm{x}=0.05,0.10)$ samples.

It is quite interesting that the $\mathrm{Cu}_{0.979} \mathrm{Ag}_{0.02} \mathrm{Zn}_{0.001} \mathrm{AlO}_{2}$ sample shows a higher value not only of the electrical conductivity but also of the Seebeck coefficient at temperature above 1,000 K, compared to that of the non-doped sample. Such phenomena cannot be explained by the above mentioned general relationship between $\sigma$ and $S$. However, the energy correlated carrier mobility $\mu(\mathrm{E})$ may play a crucial role in determining $S$. According to Ref. [35], the Seebeck coefficient can be expressed by the following formula:

$$
S(T)=\frac{c_{e}}{n}+\frac{\pi^{2} k_{B}^{2} T}{3 e}\left[\frac{\partial \ln \mu(E)}{\partial E}\right]_{E=E_{F}}
$$

where $c_{\mathrm{e}}=\left(\pi^{2} k_{\mathrm{B}}^{2} T / 3 e\right) N(E)$, and $n, c_{e}, k_{\mathrm{B}}$, and $N(E)$ are carrier concentration, specific heat, the Boltzmann constant and density of states, respectively. Although the first term $c_{\mathrm{e}} / n$ of the Equation 2 is in inverse to the carrier concentration, the increase of $S$ at high temperature for the $\mathrm{Cu}_{0.979} \mathrm{Ag}_{0.02} \mathrm{Zn}_{0.001} \mathrm{AlO}_{2}$ sample suggests that the second term may play a dominant role. We could assume that addition of $\mathrm{Ag}$ and $\mathrm{Zn}$ has changed $\mu(\mathrm{E})$, and the change of the $\mu(\mathrm{E})$ affects the increase of $S$. However, further investigations such as electronic band calculations and Hall measurements are needed to clarify the effect of the addition of $\mathrm{Ag}$ and $\mathrm{Zn}$ to the Seebeck coefficient of $\mathrm{CuAlO}_{2}$.

The power factor $\left(\sigma S^{2}\right)$ calculated from the measured electrical conductivity $(\sigma)$ and Seebeck coeffieicent $(S)$ as a function of temperature is shown in Figure 5. The power factor for all samples increases with increasing temperature. The $\mathrm{Cu}_{0.979} \mathrm{Ag}_{0.02} \mathrm{Zn}_{0.001} \mathrm{AlO}_{2}$ sample shows the highest values of power factor over the investigated temperature range and the $\sigma S^{2}$ value reaches $1.26 \times 10^{-4} \mathrm{~W} / \mathrm{mK}^{2}$ at $1,060 \mathrm{~K}$. To the best our knowledge, this is the highest value among the previously reported values for $\mathrm{CuAlO}_{2}$-related bulk materials.

Figure 6 shows the temperature dependence of the thermal conductivity $(\kappa)$ of the samples. It is expected that the addition of heavier elements such as $\mathrm{Ag}$ to the $\mathrm{Cu}$-sites in $\mathrm{CuAlO}_{2}$ will lead to a lower thermal conductivity than that of the non-doped sample due to the increase of phonon scattering induced by additional elements. However, the observed results showed that the values of the thermal conductivity with the addition of $\mathrm{Ag}, \mathrm{Ni}$ and $\mathrm{Zn}$ are larger compared with the non-doped sample. The $\kappa$ value is of about $10 \%$ larger for the $\mathrm{Cu}_{0.979} \mathrm{Ag}_{0.02} \mathrm{Zn}_{0.001} \mathrm{AlO}_{2}$ sample than that for the non-doped one. The total thermal conductivity $\kappa$ consists of the phonon contribution $\kappa_{\mathrm{ph}}$ and the electronic contribution $\kappa_{\mathrm{e}}$, i.e. $\kappa=\kappa_{\mathrm{ph}}+\kappa_{\mathrm{e}}$. The electronic component can be estimated using the Wiedemann-Franz law, $\kappa_{\mathrm{e}}=$ $L_{0} T \sigma$, where $L_{0}=2.45 \times 10^{-8} \mathrm{~W} \Omega / \mathrm{K}^{2}$ is the Lorenz number and $T$ is absolute temperature. The calculated $\kappa_{\mathrm{e}}$ for all samples in this study is only about $0.1 \%$ of the total thermal conductivity $\kappa$. This suggests that the main contribution to the total thermal conductivity is the phonon part, and the electronic part can be negligible. The reason why the addition of $\mathrm{Ag}$ or $\mathrm{Ag}$ and $\mathrm{Ni}$ results in a larger $\kappa$ suggests that there might be a contribution of secondary phase of $\mathrm{CuO}$ with high thermal conductivity (33 W/mK at RT [36]) to the total thermal conductivity. Moreover, the addition of Ag, Ni and $\mathrm{Zn}$ results in samples with larger grain size compared to that of the non-doped sample (see Figure 2). Thus, 
the observed increase in $\kappa$ for the $\mathrm{Cu}_{0.979} \mathrm{Ag}_{0.02} \mathrm{Zn}_{0.001} \mathrm{AlO}_{2}$ sample is probably attributed to the increase in the $\kappa_{\mathrm{ph}}$ due to the reduction of phonon scattering caused by increasing in the grain size.

Figure 5. Temperature dependence of the power factor of $\mathrm{CuAlO}_{2}, \mathrm{Cu}_{0.98} \mathrm{Ag}_{0.02} \mathrm{AlO}_{2}$, $\mathrm{Cu}_{0.979} \mathrm{Ag}_{0.02} \mathrm{Ni}_{0.001} \mathrm{AlO}_{2}$ and $\mathrm{Cu}_{0.979} \mathrm{Ag}_{0.02} \mathrm{Zn}_{0.001} \mathrm{AlO}_{2}$ samples.

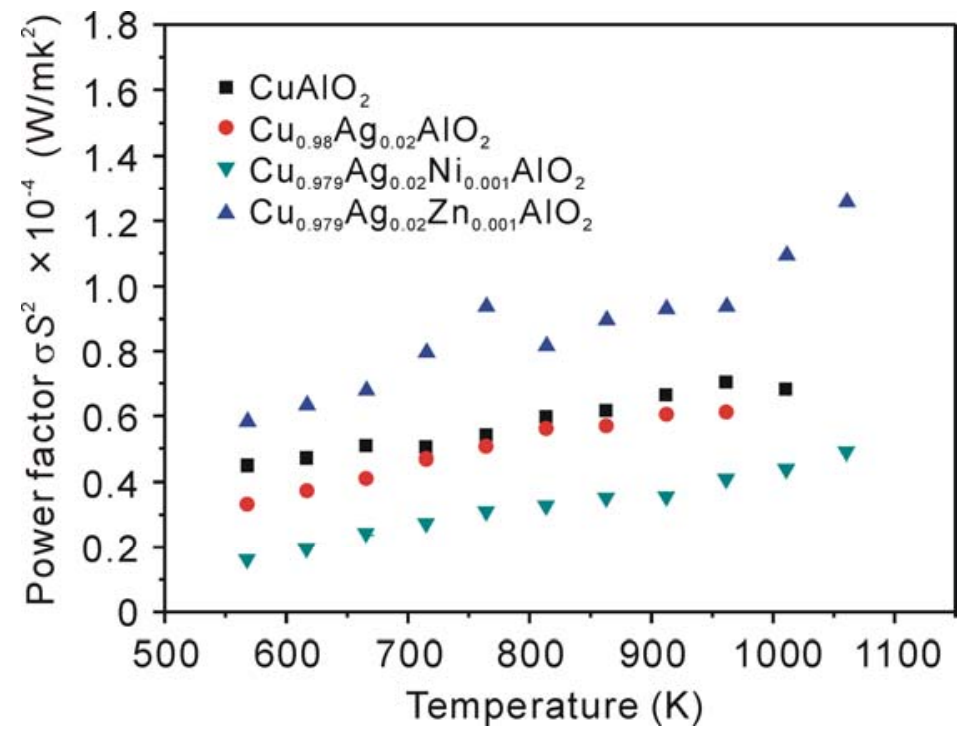

Figure 6. Temperature dependence of the thermal conductivity $\kappa$ for the samples.

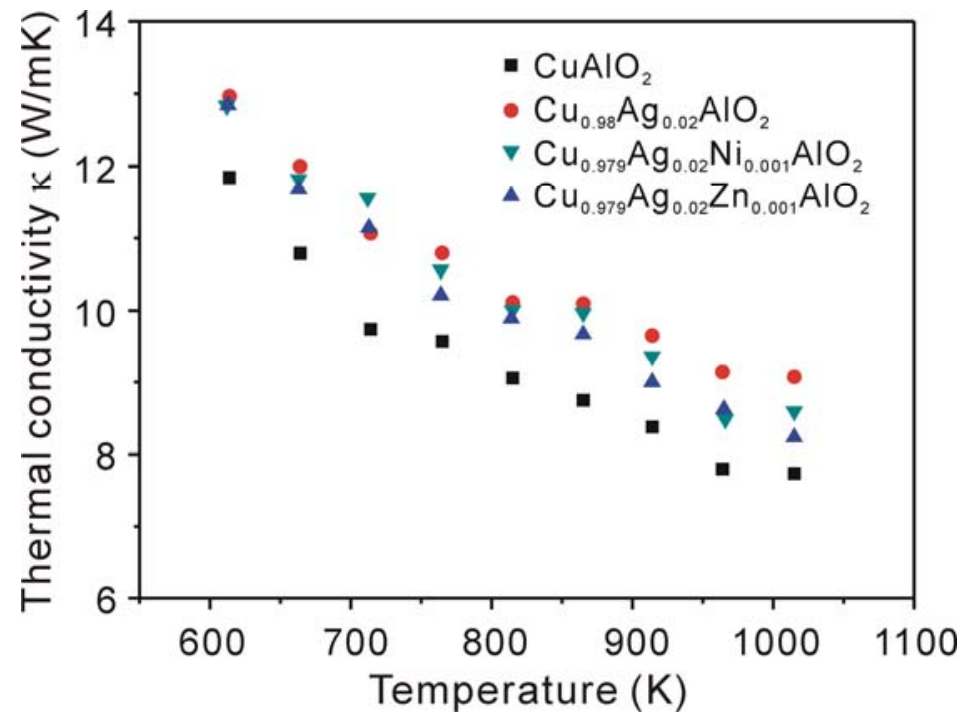

The highest dimensionless figure of merit $Z T$ of about 0.016 was obtained for the $\mathrm{Cu}_{0.979} \mathrm{Ag}_{0.02} \mathrm{Zn}_{0.001} \mathrm{AlO}_{2}$ sample at $1,060 \mathrm{~K}$. Although this value is not high enough for practical application, the improvement of thermoelectric performance in this study is significant and important for this system which contains cheep elements. Further investigations using several approaches, e.g., an optimization of carrier concentration and improving the density by applying other sintering procedure, are expected to improve the $Z T$ of $\mathrm{CuAlO}_{2}$. 


\section{Conclusions}

Polycrystalline bulk copper aluminate $\mathrm{Cu}_{1-\mathrm{x}-\mathrm{y}} \mathrm{Ag}_{\mathrm{x}} \mathrm{B}_{\mathrm{y}} \mathrm{AlO}_{2}(\mathrm{x}=0,0.02$ and $\mathrm{y}=0,0.001, \mathrm{~B}=\mathrm{Ni}$ or $\mathrm{Zn}$ ) were prepared by spark plasma sintering and subsequent thermal treatment. The effect of the addition of $\mathrm{Ag}, \mathrm{Ni}$ and $\mathrm{Zn}$ for $\mathrm{Cu}$-sites on the thermoelectric properties of $\mathrm{CuAlO}_{2}$ was investigated. The results of XRD measurements revealed that the addition of $\mathrm{Ag}$ and $\mathrm{Zn}$ enhanced the formation of $\mathrm{CuAlO}_{2}$ phase, whereas the addition of $\mathrm{Ag}$ and Ni inhibited the reaction between the starting materials of $\mathrm{CuO}$ and $\mathrm{Al}_{2} \mathrm{O}_{3}$. The addition of $\mathrm{Ag}$ and $\mathrm{Zn}$ was found to increase the electrical conductivity over the measured temperature range and the Seebeck coefficient above 1,000 K compared to those of the non-doped $\mathrm{CuAlO}_{2}$ sample, while the addition of $\mathrm{Ag}$ or $\mathrm{Ag}$ and $\mathrm{Ni}$ decreased the electrical conductivity. All the doped samples showed a higher thermal conductivity than that of non-doped sample. The power factor was substantially improved by the addition of $\mathrm{Ag}$ and $\mathrm{Zn}$. The maximum power factor reaches a value of $1.26 \times 10^{-4} \mathrm{~W} / \mathrm{mK}^{2}$ for $\mathrm{Cu}_{0.979} \mathrm{Ag}_{0.02} \mathrm{Zn}_{0.001} \mathrm{AlO}_{2}$ sample at 1,060 $\mathrm{K}$, enable a $Z T$ value of 0.016 to be reached.

\section{Acknowledgements}

The authors thank Yuji Takahashi and Yoshiya Mizushima for their contributions to sample preparation by using SPS and Johannes Steen Bang for sample preparation for thermoelectric measurements.

\section{References}

1. Snyder, G.J.; Toberer, E.S. Complex thermoelectric materials. Nat. Mater. 2008, 7, 105-114.

2. Bhandari, C.M.; Rowe, D.M. Optimization of carrier concentration. In CRC Handbook of Thermoelectrics; Rowe. D.M., Ed.; CRC Press: Boca Raton, FL, USA, 1995; pp. 43-53.

3. Ohtaki, M.; Araki, K.; Yamamoto, K. High thermoelectric performance of dually doped $\mathrm{ZnO}$ ceramics. J. Electron. Mater. 2009, 38, 1234-1238.

4. Poudel, B.; Hao, Q.; Ma, Y.; Lan, Y.; Minnich, A.; Yu, B.; Yan, X.; Wang, D.; Muto, A.; Vashaee, D.; Chen, X.; Liu, J.; Dresselhaus, M.S.; Chen, G.; Ren, Z. High-thermoelectric performance of nanostructured bismuth antimony telluride bulk alloys. Science 2008, 320, 634-638.

5. Scherrer, H.; Scherrer, S. Thermoelectric properties of bismuth antimony telluride solid solutions. In Thermoelectrics Handbook: Macro to Nano; Rowe, D.M.; CRC Press: Boca Raton, FL, USA, 2006; p. 27.

6. Hsu, K.F.; Loo, S.; Guo, F.; Chen, Y.; Dyck, J.S.; Uher, C.; Hogan, T.; Polychroniadis, E.K.; Kanatzidis, M.G. Cubic $\mathrm{AgPb}_{\mathrm{m}} \mathrm{SbTe}_{2+\mathrm{m}}$ : bulk thermoelectric materials with high figure of merit. Science 2004, 303, 818-821.

7. Rowe, D.M.; Shukla, V.S. The effect of phonon-grain boundary scattering on the lattice thermal conductivity and thermoelectric conversion efficiency of heavily doped fine-grained, hot-pressed silicon germanium alloy. J. Appl. Phys. 1981, 52, 7421-7426.

8. Zhang, Q.; He, J.; Zhu, T.J.; Zhang, S.N.; Zhao, X.B.; Tritt, T.M. High figures of merit and natural nanostructures in $\mathrm{Mg}_{2} \mathrm{Si}_{0.4} \mathrm{Sn}_{0.6}$ based thermoelectric materials. Appl. Phys. Lett. 2008, 93, 102109. 
9. Caillat, T.; Fleurial, J.-P.; Borshchevsky, A. Preparation and thermoelectric properties of semiconducting $\mathrm{Zn}_{4} \mathrm{Sb}_{3}$. J. Phys. Chem. Solids 1997, 58, 1119-1125.

10. Shi, X.; Kong, H.; Li, C.-P.; Uher, C.; Yang, J.; Salvador, J.R.; Wang, H.; Chen, L.; Zhang, W. Low thermal conductivity and high thermoelectric figure of merit in $n$-type $\mathrm{Ba}_{\mathrm{x}} \mathrm{Yb}_{\mathrm{y}} \mathrm{Co}_{4} \mathrm{Sb}_{12}$ double-filled skutterudites. Appl. Phys. Lett. 2008, 92, 182101.

11. Sakurada, S.; Shutoh, N. Effect of Ti substitution on the thermoelectric properties of (Zr,Hf)NiSn half-Heusler compounds. Appl. Phys. Lett. 2005, 86, 082105.

12. Kim, J.H.; Okamoto, N. L.; Kishida, K.; Tanaka, K.; Inui, H. High thermoelectric performance of type-III clathrate compounds of the Ba-Ge-Ga system. Acta. Mater. 2006, 54, 2057-2062.

13. Terasaki, I.; Sasago, Y.; Uchinokura, K. Large thermoelectric power in $\mathrm{NaCo}_{2} \mathrm{O}_{4}$ single crystals. Phys. Rev.B 1997, 56, R12685-R12687.

14. Masset, A.C.; Michel, C.; Maignan, A.; Hervieu, M.; Toulemonde, O.; Studer, F.; Raveau, B.; Hejtmanek, J. Misfit-layered cobaltite with an anisotropic giant magnetoresistance: $\mathrm{Ca}_{3} \mathrm{Co}_{4} \mathrm{O}_{9}$. Phys. Rev. B 2000, 62, 166-175.

15. Ohtaki, M.; Tsubota, T.; Eguchi, K.; Arai, H. High-temperature thermoelectric properties of $\left(\mathrm{Zn}_{1-\mathrm{x}} \mathrm{Al} \mathrm{x}_{\mathrm{x}}\right)$ O. J. Appl.Phys. 1996, 79, 1816-1818.

16. Ohta, S.; Ohta, H.; Koumoto, K. Grain size dependence of thermoelectric performance of Nbdoped $\mathrm{SrTiO}_{3}$ polycrystals. J. Ceram. Soc. Jpn. 2006, 114, 102-105.

17. Koumoto, K.; Koduka, H.; Seo, W.S. Thermoelectric properties of single crystal $\mathrm{CuAlO}_{2}$ with a layered structure. J. Mater. Chem. 2001, 11, 251-252.

18. Park, K.; Ko, K.Y.; Seo, W.-S. Thermoelectric properties of $\mathrm{CuAlO}_{2}$. J. Euro. Ceram. Soc. 2005, 25, 2219-2222.

19. Tsuboi, N.; Takahashi, Y.; Kobayashi, S.; Shimizu, H.; Kato, K.; Kaneko, F. Delafossite $\mathrm{CuAlO}_{2}$ films prepared by reactive sputtering using $\mathrm{Cu}$ and $\mathrm{Al}$ targets. J. Phys. Chem. Solids 2003, 64, 1671-1674.

20. Cai, J.; Gong, $\mathrm{H}$. The influence of $\mathrm{Cu} / \mathrm{Al}$ ratio on properties of chemical-vapor-deposition-grown p-type Cu-Al-O transparent semiconducting films. J. Appl. Phys. 2005, 98, 033707.

21. Yanagi, H.; Inoue, S.; Ueda, K.; Kawazoe, H.; Hosono, H.; Hamada, N. Electronic structure and optoelectronic properties of transparent p-type conducting $\mathrm{CuAlO}_{2}$. J. Appl. Phys. 2000, 88, 4159-4163.

22. Ishiguro, T.; Ishizawa, N.; Mizutani, N.; Kato, M.; Tanaka, K.; Marumo, F. Charge-density distribution in crystals of $\mathrm{CuAlO}_{2}$ with d-s hybridization. Acta Cryst. 1983, B39, 564-569.

23. Kawazoe, H.; Yasukawa, M.; Hyodo, H.; Kurita, M.; Yanagi, H.; Hosono, H. P-type electrical conduction in transparent thin films of $\mathrm{CuAlO}_{2}$. Nature 1997, 389, 939-942.

24. Park, K.; Ko, K.Y.; Seo, W.-S. Effect of partial substitution of $\mathrm{Ca}$ for $\mathrm{Al}$ on the microstructure and high-temperature thermoelectric properties of $\mathrm{CuAlO}_{2}$. Mater. Sci. Eng. B 2006, 129, 1-7.

25. Park, K.; Ko, K.Y.; Seong, J.K.; Nahm, S. Microstructure and high-temperature thermoelectric properties of polycrystalline $\mathrm{CuAl}_{1-\mathrm{x}} \mathrm{Mg}_{\mathrm{x}} \mathrm{O}_{2}$ ceramics. J. Euro. Ceram. Soc. 2007, 27, 3735-3738.

26. Park, K.; Ko, K.Y.; Kwon, H.-C.; Nahm, S. Improvement in thermoelectric properties of $\mathrm{CuAlO}_{2}$ by adding $\mathrm{Fe}_{2} \mathrm{O}_{3}$. J. Alloys Compd. 2007, 437, 1-6.

27. Lalic, M.V.; Mestnik-Filho, J.; Carbonari, A.W.; Saxena, R.N. Changes induced by the presence of $\mathrm{Zn}$ or Ni impurity at $\mathrm{Cu}$ sites in $\mathrm{CuAlO}_{2}$ delafossite. Solid State Commun. 2003, 125, 175-178. 
28. Shibasaki, S.; Kobayashi, W.; Terasaki, I. Transport properties of the delafossite Rh oxide $\mathrm{Cu}_{1-\mathrm{x}} \mathrm{Ag}_{\mathrm{x}} \mathrm{Rh}_{1-\mathrm{y}} \mathrm{Mg}_{\mathrm{y}} \mathrm{O}_{2}$ : Effect of $\mathrm{Mg}$ substitution on the resistivity and Hall coefficient. Phys. Rev. $B$ 2006, 74, 235110.

29. Shannon, R.D.; Prewitt, C.T. Effective ionic radii in oxides and fluorides. Acta Cryst. 1969, B25, 925-946.

30. Hamada, I.; Katayama-Yoshida, H. Energetics of native defects in $\mathrm{CuAlO}_{2}$. Physica B 2006, 376$377,808-811$.

31. Ingram, B.J.; González, G.B.; Mason, T.O.; Shahriari, D.Y.; Barnabè, A.; Ko, D.; Poeppelmeier, K.R. Transport and defect mechanisms in cuprous delafossites. 1. Comparison of hydrothermal and standard solid-state synthesis in $\mathrm{CuAlO}_{2}$. Chem. Mater. 2004, 16, 5616-5622.

32. Wongcharoen, N.; Gaewdang, T. Thermoelectric properties of Ni-doped $\mathrm{CuAlO}_{2}$. Physica Procedia 2009, 2, 101-106.

33. Ingram, B.J.; Mason, T.O.; Asahi, R.; Park, K.T.; Freeman, A.J. Electronic structure and small polaron hole transport of copper aluminate. Phys. Rev. B 2001, 64, 155114.

34. Rowe, D.M. General principles and basic considerations. In Thermoelectrics handbook: Macro to Nano; Rowe, D.M., Ed.; CRC Press: Boca Raton, FL, USA, 2006; p. 1.

35. Xu, G.; Funahashi, R.; Shikano, M.; Pu, Q.; Liu, B. High temperature transport properties of $\mathrm{Ca}_{3-\mathrm{x}} \mathrm{Na}_{\mathrm{x}} \mathrm{Co}_{4} \mathrm{O}_{9}$ system. Solid State Commun. 2002, 124, 73-76.

36. Liu, M.-S.; Lin, M.C.-C.; Huang, I.-T.; Wang, C.-C. Enhancement of thermal conductivity with $\mathrm{CuO}$ for Nanofluids. Chem. Eng. Technol. 2006, 29, 72-77.

(C) 2010 by the authors; licensee Molecular Diversity Preservation International, Basel, Switzerland. This article is an open-access article distributed under the terms and conditions of the Creative Commons Attribution license (http://creativecommons.org/licenses/by/3.0/). 